\title{
Subtrochanteric Femur Fracture Healing Time Compared among Operated Young, Middle Aged Indian Adults
}

\author{
Chintan Harilal Patel ${ }^{1}$, Kruti Chintan Patel ${ }^{2}$, Vishal Bhagwandas Panchal ${ }^{3}$ \\ ${ }^{1}$ King Edward VII Memorial Hospital \& Seth G. S. Medical College, Mumbai \\ ${ }^{2}$ Grant Government Medical College \& Sir J. J. Group of Hospitals, Mumbai \\ ${ }^{3}$ King Edward VII Memorial Hospital \& Seth G. S. Medical College, Mumbai
}

\begin{abstract}
They were further grouped according to the age and gender of the operated patient. Statistical significancewas calculated for establishing any correlation, if any, between the age or gender and the fracture healing time in the post-operated patient. This study did not find any such correlation.
\end{abstract}

Keywords: subtrochanteric, femur, fracture healing, age, gender

\section{Introduction}

Subtrochanteric fractures as any other metaphyseodiaphyseal fractures have a unique personality and eventual management concerns. Fracture union in these cases is of particular interest owing to precarious blood supply, damaged in the setting of fracture or overzealous tissue dissection. There are various systems of classification for subtrochanteric fractures [1]. In our study we used the classification given by Seinsheimer, which in addition to the location and orientation of fracture lines, also considers the number of major bone fragments. The high popularity enjoyed by this classification among traumatologists, is due to its undeniable contribution in estimating the difficulties encountered during fracture reduction and fixation.

Subtrochanteric fractures, as an individual group, possess certain unique features related to the natural history of healing, and management needed to accelerate return to a functional state. They pose certain anatomical, biological and biomechanical challenges and typically give high complication rates [2]. Fractures in the subtrochanteric region present challenges in achieving stable fixation and appropriate reduction. This vital aspect of fracture fixation has been highlighted in multiple studies that have evaluated the outcome of various modes of fracture fixation in subtrochanteric fractures.

This study intends to demonstrate and highlight the different rates of fracture union achieved in subtrochanteric fractures, among different age and gender groups, in skeletally mature femurs. Only those between 25 and 50 years of age were includedto rule out any confounding effect of unfused epiphysis in the adolescent or osteoporosis in the elderly [3]. This study can lay groundwork for management and prognostication of subtrochanteric fractures in young and middle aged population.

\section{Methods}

This study was intended to measure the radiological outcomes, in terms of fracture union, using the follow-up radiographs of post-operative patients of subtrochanteric femur fracture among the 25-50 year Indian population.

1) We measured the specific radiological parameters on the follow-up radiographs of patients aged $>25$ yrs and $<50$ yrs for post-operative outcome of subtrochanteric femur fracture.

2) For this study, fracture was considered to have united when 3 of the 4 cortices were bridged on two separate radiograph views and when Hammer scale 2 was achieved [4].

3) These parameters were studied among the various groups into which the patients are classified with respect to the age and gender.

The radiological follow-up data of 53 patients at King Edward Memorial VII Hospital (KEMH), Mumbai, from July 2012 to November 2013 was collected and analyzed. Follow-up radiographs till fracture union upto a maximum of 9 months were studied.

All Patients operated at KEMH for unilateral subtrochanteric femur fracture between Age $>25$ years and $<50$ years were included in this study. The subtrochanteric fractures were reduced and fixed with acceptable criteria either by condylar screw plating or intramedullary nailing. Pathological, open fractures were excluded from the study.

The statistical tests used were one-way ANOVA test for agegroup and fracture healing time comparison; independent ttest for gender and fracture healing time comparison.

After processing of the data, the cases were divided into various groups, and the differences in the various parameters, especially the time to fracture union were studied and analyzed. The cases were mainly divided according to the following criteria: 
1) Different age groups (25-34 years, 35-44 years, 45-50 years): (Table 1)

Table 1: Age classification of patients

\begin{tabular}{|c|c|c|}
\hline $\begin{array}{c}\text { Age } \\
\text { (years) }\end{array}$ & $\begin{array}{c}\text { Cases } \\
(n)\end{array}$ & $\begin{array}{c}\text { Fracture healing time of individual } \\
\text { patients (weeks) }\end{array}$ \\
\hline $25-34$ & 13 & $9,12,18,14,14,12,14,12,12,10,12,12,14$ \\
\hline $35-44$ & 28 & $\begin{array}{c}12,9,12,14,10,12,16,10,12,10,10,14,9,16, \\
12,18,12,12,12,20,12,10,20,14,14,18,12,10\end{array}$ \\
\hline $45-50$ & 12 & $18,10,12,14,12,10,24,12,14,14,10,16$ \\
\hline
\end{tabular}

2) Male and female groups: (Table 2)

Table 2: Gender classification of patients

\begin{tabular}{|c|c|c|}
\hline Gender & Cases(n) & $\begin{array}{c}\text { Fracture healing time of individual } \\
\text { patients (weeks) }\end{array}$ \\
\hline Males & 28 & $12,12,10,12,12,12,20$, \\
& & $10,14,10,12,16,9,12$, \\
& & $12,10,12,24,10,12,18$, \\
& & $12,14,12,12,18,10,14$ \\
\hline Females & 25 & $18,10,9,20,12,14,14$, \\
& & $9,14,10,14,12,16,12$, \\
& & $12,14,16,10,18,14$, \\
& & $12,12,14,14,10$ \\
\hline
\end{tabular}

\section{Results}

Post-operativesubtrochanteric fractures $(n=53)$ were studied. They were classified according to Seinsheimer's classification. Type IIIA constituted the maximum number of cases $(n=11)$ followed by Type V $(n=10)$. Rest of 32 patients belonged to Type I $(n=4)$, IIA $(n=4)$, Type IIB $(n=5)$, Type IIC ( $n=7)$, Type IIIB (n=7) and Type IV $(n=5)$. These fractureswere either plated by dynamic condylar screw or nailed intramedullary.

The age of the patients ranged from 28 to 49 years with mean age being 38.87 years. The $35-44$ year age group had the maximum patients $(n=28)$. The study comprised of 28 males and 25 females.

All post-operative cases showed union within the stipulated 9-month period on serial follow-up radiographs. Fracture healing time was recorded in weeks when the post-operative radiograph showed at least 3 of the 4 cortices bridged coinciding in all cases with Hammer Scale 2. Fracture healing time ranged from 9 to 24 weeks with the mean being 13.04 weeks. No statistically significant relation was found between the following variables:

1) Age-group of the patient and the fracture healing time (' $p$ ' value by one-way ANOVA test: 0.628 )

2) Gender of the patient and the fracture healing time (' $p$ ' value by independent t-test: 0.788 )

\section{Discussion \&Conclusion}

Our study highlights the significance when it comes to the difference in the rates of fracture healing, if any, between different gender and age groups, in operated subtrochanteric femur fractures in young, middle aged adults.

1) The fracture healing time did not significantly correlate with the age of the patient.

2) The fracture healing time did not significantly correlate with the gender of the patient.
3) There was no incidence of nonunion in any case in the study.

\section{References}

[1] Haidukewych GJ, Langford J. Subtrochanteric Fractures. In: Buchholz RW, Court-Brown CM, Heckman JD, Tornetta III P. eds. Rockwood and Green's Fractures in Adults, vol 2, 7th ed. Philadelphia, PA: Lippincott Williams \& Wilkins; 2010:1642.

[2] Neogi DS, Trikha V, Mishra KK, Rohilla N, Yadav CS. Biological plate fixation of comminuted subtrochanteric fractures with the Dynamic Condylar Screw : A clinical study. ActaOrthop. Belg., 2009;75(4): 497-503.

[3] Malhotra N, Mithal A. Osteoporosis in Indians. Indian J. 2008 Mar;127(3):263-8.

[4] Whelan DB, Bhandari M, McKee MD, Guyatt GH, Kreder HJ, Stephen D, Schemitsch EH. Interobserver and intraobserver variation in the assessment of the healing of tibial fractures after intramedullary fixation. J Bone Joint Surg Br. 2002 Jan;84(1):15-8.

\section{Author Profile}

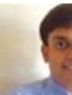

ChintanHarilal Patelreceived the M.S. (Orth) and M.B.B.S. degrees in Orthopaedic Surgery from King Edward VII Memorial Hospital \& Seth G. S. Medical College, Mumbai in 2015 and Grant Government Medical College \& Sir J. J. Group of Hospitals, Mumbai in 2009, respectively. During 2012-2015, he trained as an orthopaedic resident and registrar at King Edward VII Memorial Hospital \& Seth G. S. Medical College, Mumbai. He currently is an orthopaedic consultant and surgeon at H. J. Doshi Hindu Sabha Hospital, Mumbai.

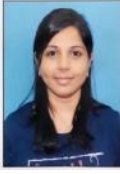

KrutiChintan Patelreceived the M.B.B.S. degree from Grant Government Medical College \& Sir J. J. Group of Hospitals, Mumbai in 2015. She is currently is a post-graduate resident in internal medicine at Grant Government Medical College \& Sir J. J. Group of Hospitals, Mumbai.

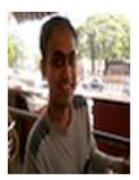

Vishal Bhagwandas Panchal received the M.B.B.S. degree from Grant Government Medical College \& Sir J. J. Group of Hospitals, Mumbai in 2009. He is currently is a post-graduate resident in preventive and social medicine at King Edward VII Memorial Hospital \& Seth G. S. Medical College, Mumbai. 